Article

\title{
The Influence of Interface Characteristics on the Adhesion/Cohesion of Plasma Sprayed Tungsten Coatings
}

\author{
Jiří Matějíček ${ }^{1, *}$, Monika Vilémová ${ }^{1}$, Radek Mušálek ${ }^{1}$, Pavel Sachr ${ }^{2}$ and Jakub Horník ${ }^{2}$ \\ 1 Department of Materials Engineering, Institute of Plasma Physics, Za Slovankou 3, 18200 Prague, \\ Czech Republic; E-Mails: vilemova@ipp.cas.cz (M.V.); musalek@ipp.cas.cz (R.M.) \\ 2 Faculty of Mechanical Engineering, Czech Technical University in Prague, Karlovo náměstí 13, \\ 12135 Prague, Czech Republic; E-Mails: pavel.sachr@fs.cvut.cz (P.S.); \\ jakub.hornik@fs.cvut.cz (J.H.) \\ * Author to whom correspondence should be addressed; E-Mail: jmatejic@ipp.cas.cz; \\ Tel.: +420-266-053-307; Fax: +420-286-586-389.
}

Received: 3 May 2013; in revised form: 5 June 2013 / Accepted: 14 June 2013 /

Published: 21 June 2013

\begin{abstract}
Tungsten is the prime candidate material for plasma facing components of future fusion devices. Plasma spraying, with its ability to coat large areas, including non-planar surfaces, with a significant thickness, is a prospective fabrication technology for components subject to moderate heat loads, e.g., the first wall of the Demonstration Reactor (DEMO). The functionality of such coatings is critically dependent on their adhesion to the underlying material. This in turn, is influenced by a variety of processing-related factors, chief among them being the state of the interface. In this study, the effects of two factors-surface roughness and the presence of thin interlayers - were investigated. Two different levels of roughness of steel substrates were induced by grit blasting, and two thin interlayers - titanium ( $\mathrm{Ti}$ ) and tungsten $(\mathrm{W})$ - were applied by physical vapor deposition prior to plasma spraying of W by a Water Stabilized Plasma (WSP) torch. Coating adhesion was determined by a shear adhesion test. The structures of the coatings and the interfaces, as well as the characteristics of the fractured surfaces, were observed by SEM.
\end{abstract}

Keywords: tungsten (W); plasma spraying; physical vapor deposition (PVD); adhesion; cohesion; plasma-facing components; nuclear fusion 


\section{Introduction}

Nuclear fusion is a prospective energy source for the future, which brings the promise of a safe, relatively clean and large-scale energy source. Its successful realization is critically dependent on the availability of materials able to function in the extremely harsh conditions of a fusion device. In the recently published "Fusion Roadmap" [1], three out of seven major challenges to its realization as an energy source are related to materials. Among the milestones on this road are the International Thermonuclear Experimental Reactor (ITER), currently under construction, whose purpose is to demonstrate the technical feasibility of a fusion reactor and to integrate and test the necessary components and technologies, and the Demonstration Reactor (DEMO), being the successor of ITER, whose aim is to demonstrate the feasibility of a complete, economically viable fusion power plant.

Tungsten is one of the candidate materials for the plasma facing components of ITER, and the prime candidate for the entire plasma facing surface of DEMO [2]. These components must withstand the high heat and particle fluxes from the plasma. Among the favorable properties of tungsten are its high melting point, low vapor pressure, good thermal conductivity, high temperature strength and stability, high threshold for sputtering; also, it does not form hydrides or co-deposits with tritium. On the other hand, its high atomic number makes it a highly undesirable impurity in plasma, while further disadvantages include its brittle nature and difficult machining [3,4]. Tungsten plasma facing components (also termed "armor") can be fabricated by different methods, including bulk material processing (chiefly powder metallurgy + joining) and different coating techniques (physical and chemical vapor deposition (PVD, CVD) and plasma spraying (PS)) [5,6]. This paper concerns plasma spraying, whose advantages include the following [7]:

- Ability to coat large-area components, including non-planar shapes, with significant thickness

- A single-step manufacturing technology, without the need for further joining

- Possibility of in-situ repair of damaged parts

- Easy formation of graded composites

- Moderate heat input to the coated parts

- High strain tolerance

The main disadvantage of plasma sprayed coatings is their low thermal conductivity, which makes them applicable only in regions of low to moderate heat fluxes [8].

As with all coatings, adhesion is a critical issue; without sufficient adhesion, all other coating functions will be lost. Different coating adhesion mechanisms are usually divided into three groups: mechanical, physical, chemical/metallurgical $[9,10]$. There are numerous factors that influence adhesion - e.g., the roughness, temperature and composition of the substrate, the presence/absence of adsorbates, bondcoats/interlayers, temperature and velocity of the impacting particles, powder feed rate, spraying pattern, torch traverse velocity, splat-substrate wetting, splat spreading, solidification, splashing, oxidation of splats and substrate, residual stress, coating thickness, etc., many of which are interconnected. Some of these factors will be briefly reviewed here, together with selected case studies.

Mechanical interlocking is generally accepted as the main adhesion mechanism in most thermal spray methods. Therefore, substrate roughening, e.g., by grit blasting is a common practice in thermal spraying. In general, higher substrate roughness leads to higher adhesion [11-13]; this has been observed 
both for the deposition of fully molten (plasma sprayed) and semi-molten (HVOF-sprayed) particles [14]. However, for higher roughness range $(>50 \mu \mathrm{m})$, adhesion was also found to decrease with increasing roughness [15]. The interlocking is most effective under the center of the splat, where the pressure upon impact is highest, and decreases towards the splat periphery [10]. Pressure impulse at the point of impact increases with the kinetic energy of the incident droplet. Thermally induced bonding can occur when the conditions for incipient melting of the substrate are met [10], which generally leads to improved bond strength. The necessary temperatures of the droplet and the substrate were calculated in [16] for a variety of coating/substrate combinations. Furthermore, there has to be enough time for the splat to melt the substrate, and both to solidify before the impact pressure is dissipated [10]. Localized substrate melting promotes the formation of metallurgical bonds, e.g., the formation of intermetallic compounds at the interface [16]. However, under typical conditions of thermal spraying, the interdiffusion distance is of the order of units of $\mathrm{nm}$ [10]. Even in the case of mutually insoluble materials (e.g., $\mathrm{W}$ and $\mathrm{Cu}$ ) where no reaction interlayer forms, local melting promotes closer contact of the two materials and thus improves the bonding [16]. For the above reasons, higher deposition temperatures generally lead to improved adhesion, but they may also induce or increase oxidation of metallic materials, which generally hinder adhesion $[10,11]$. Therefore, a compromise has to be made for a specific material combination.

The first layer of deposited splats represents the contact between the coating and the substrate. Therefore, their formation is crucial for the development of adhesion. An important factor in this aspect is the deposition temperature. In many materials, a transition temperature was found, above which contiguous, disk-shaped splats typically form, and below which they tend to splash and fragment [17]. This has been attributed to adsorbates and condensates on the substrate surface [18], which evaporate under the hot splat and form a gaseous barrier between the two surfaces or are trapped under the splat in the form of bubbles $[19,20]$, in both cases increasing the thermal resistance. On heated surfaces, these adsorbates/condensates are evaporated and the splat-substrate contact is improved [21]. Disk-shaped splats are generally preferred, as they are associated with high adhesion and cohesion, low porosity and good mechanical and thermal properties of the coating. Coatings formed from splashed splats typically have poor adhesion and cohesion, and high porosity [20]. The detrimental effects of splashing include the formation of voids that are difficult to fill by the subsequent droplets, reduced time for substrate melting and reduced pressure in the splash drops [10]. The presence of oxides or hydroxides at the interface might inhibit the contact between the two materials; if these are thin enough, however, localized substrate melting, jetting and interdiffusion are still possible [22]. Preheating appears to improve the wettability of the substrate by the particles, thereby enhancing the adhesion, even in cases of splashing [15]. Rough substrates often lead to splats with higher thickness and lower diameter [10], while their splashing is suppressed [23]. Substrate roughness also presents higher thermal resistance, with only limited contact points, and this leads to longer thermal interaction [10]. Mutual bonding between the splats is also important, as coating delamination can occur at the interface (adhesive failure) or within the coating (cohesive failure), or in a combination of both. Among the factors positively affecting interparticle bonding (cohesion) are the particle temperature and deposition temperature. Particle velocity, although generally accepted to produce higher density coatings, was found to be rather detrimental to interlamellar bonding [24]. 
In cases of largely dissimilar materials, bonding interlayers (or "bondcoats") are often introduced. The most common example is thermal barrier coatings in jet engines, where sprayed Ni- or Co-based bondcoat is introduced between the Ni-based turbine blade and plasma sprayed zirconia-based topcoat. In [25], tungsten as plasma facing material was deposited by vacuum plasma spraying (VPS) on graphite with $\mathrm{SiC}$ and $\mathrm{Ti}$ interlayer; only coatings with $\mathrm{Ti}$ exhibited sufficient adhesion strength in thermal exposure tests. In [26], the case of VPS-W on $\mathrm{Cu}$ was considered by finite element modeling (FEM), with interlayers of $\mathrm{W} / \mathrm{Cu}, \mathrm{Ti}$ and $\mathrm{NiCrAl}$. From these simulations, the $\mathrm{W} / \mathrm{Cu}$ appeared the best in reducing the stress concentration at the interface without significant increase of the surface temperature. Such mixed layers can be advantageously formed by plasma spraying [27-29]. VPS and PVD were successfully used to produce functionally graded Eurofer97/tungsten coatings that proved suitable as interlayers for joining Eurofer97 and tungsten bulk material by diffusion bonding [30]. The structures bonded this way survived several thermal cycles up to $650^{\circ} \mathrm{C}$, without new phase formation or change in chemical composition, and showed a marked improvement over direct diffusion bonding.

This paper focuses on the adhesion of plasma sprayed tungsten on steel substrates. Two factors are considered - substrate roughness and the presence of $\mathrm{W}$ and Ti interlayers. The shear adhesion test is complemented by detailed characterization of single splats, interfaces and the fracture surfaces.

\section{Experimental Section}

For the experiments, six conditions of the substrates were used: bare steel substrates with two levels of roughness (grit-blasted, termed 'fine' and 'coarse') and steel substrates with two types of thin interlayers - Ti and $\mathrm{W}$, again at two roughness levels each (as-machined and grit-blasted substrates). Ti was chosen as a compliant interlayer with the prospect of reducing the stress concentration at the $\mathrm{W} / \mathrm{Fe}$ interface, caused mainly by the different thermal expansion. Ti was also successfully used in joining of $\mathrm{W}$ to steel by hot isostatic pressing (HIP) [31]. The W interlayer was tested because of its expected good adhesion to the substrate and chemical affinity to the sprayed coating (same element). Low alloyed steel of S235JRC (1.0122) type was used for all the substrates; substrate dimensions were $5 \times 10 \times 30 \mathrm{~mm}$ for the shear adhesion tests and $2.5 \times 25 \times 25 \mathrm{~mm}$ for the observation of individual splats and coating cross sections. Different roughness levels of the bare steel substrates were achieved by different sizes of the alumina grit and air pressure during the grit blasting. Roughness was measured either after grit blasting (bare steel substrates) or after the PVD coating (substrates coated with Ti and W), using a Surtronic 3P surface profilometer (Rank Taylor Hobson, Leicester, UK). The roughness values are presented in Table 1.

Magnetron sputtering of the Ti and $\mathrm{W}$ interlayers was performed in a Hauzer Flexicoat 850 (Hauzer Techno Coating, Venlo, The Netherlands) equipment. First, the samples were ultrasonically cleaned in acetone, flushed with ethanol and dried, before insertion in the coating chamber. The chamber was evacuated to $2 \times 10^{-5} \mathrm{mbar}$ and preheated. The targets were cleaned for $15 \mathrm{~min}$ and the samples were cleaned for $20 \mathrm{~min}$ by Ar ion bombardment, with plasma current $60 \mathrm{~A}$ and bias $200 \mathrm{~V}$. The deposition conditions are summarized in Table 2.

The W coatings were sprayed by a WSP ${ }^{\circledR}$ water stabilized plasma torch (Institute of Plasma Physics, Prague, Czech Republic), using a 5:1 mixture of tungsten (Alldyne, Huntsville, AL, USA; 63-80 $\mu \mathrm{m}$ ) and tungsten carbide (Osram, Bruntál, Czech Republic; 40-80 $\mu \mathrm{m}$ ) powders. The WC is a sacrificial 
additive, undergoing decarburization during spraying; the carbon reacts with oxygen, making less of it available for oxidizing the tungsten [32]. X-ray diffraction was used to check that the WC converted completely to $\mathrm{W}$. The spraying parameters were as follows: torch current $500 \mathrm{~A}$, powder feed rate $33 \mathrm{~kg} / \mathrm{h}$, carrier gas $\mathrm{Ar}+7 \% \mathrm{H}_{2}$, feeding distance $35 \mathrm{~mm}$, spraying distance $200 \mathrm{~mm}$. All substrates were preheated to $160{ }^{\circ} \mathrm{C}$ by one passage of the torch prior to coating deposition. The substrate temperature was monitored by an infrared camera. Samples for the observation of individual splats were produced by one fast sweep of the torch in front of the substrates at $500 \mathrm{~mm} / \mathrm{s}$ traverse velocity. Full coatings for the adhesion tests and metallographic observations were produced by a rectangular meandering pattern across all substrates at a traverse velocity of $300 \mathrm{~mm} / \mathrm{s}$. To prevent overheating of the samples, each deposition cycle was followed by several cooling cycles (again with $\mathrm{Ar}+7 \% \mathrm{H}_{2}$ as the cooling gas, helping to suppress oxidation) until the deposition temperature decreased from $\sim 250{ }^{\circ} \mathrm{C}$ to $\sim 160{ }^{\circ} \mathrm{C}$. The resulting coating thickness was about $650 \mu \mathrm{m}$.

The adhesion strength was measured using a standardized shear test (EN 15340) [33]. The main advantage of the shear test, compared to the common tensile adhesion test, is the absence of glue, which may otherwise affect the results, and the relatively uncomplicated sample and test configuration [34]. The test samples were prepared in the shape of a prism with dimensions of $10 \times 5 \times 30 \mathrm{~mm}$; coatings were deposited on the $10 \times 5 \mathrm{~mm}$ face. The test was performed using a universal tensile test machine Instron 1362 (Instron, High Wycombe, UK). Loading was applied in the direction perpendicular to the sample longitudinal axis by means of a carbide cutting edge SPEW 1204 ADEN: 8230 (Pramet Tools, Šumperk, Czech Republic) moving at velocity of $3 \mathrm{~mm} / \mathrm{min}$.

Table 1. Overview of surface conditions prior to plasma spraying.

\begin{tabular}{cccc}
\hline Notation & Surface treatment & Interlayer & Roughness Ra $(\mu \mathbf{m})$ \\
\hline R1 & grit-blasted, coarse & - & $7.8 \pm 0.4$ \\
R2 & grit-blasted, fine & - & $5.4 \pm 0.2$ \\
T1 & as-machined & Ti & $1.7 \pm 0.2$ \\
T2 & grit-blasted, fine & Ti & $6.0 \pm 0.6$ \\
W1 & as-machined & W & $1.6 \pm 0.1$ \\
W2 & grit-blasted, fine & W & $5.6 \pm 0.6$ \\
\hline
\end{tabular}

Table 2. Magnetron sputtering parameters for the Ti and $\mathrm{W}$ interlayers.

\begin{tabular}{lcc}
\hline Parameter & Ti & W \\
\hline Chamber preheat $\left({ }^{\circ} \mathrm{C}\right)$ & 400 & 250 \\
Process pressure $($ mbar $)$ & $2 \times 10^{-3}$ & $2 \times 10^{-3}$ \\
Deposition time $(\mathrm{h})$ & 3 & 3 \\
Ar flow rate $(\mathrm{sccm})$ & 95 & 90 \\
Cathode power $(\mathrm{kW})$ & $2 \times 4$ & $1 \times 4$ \\
Bias $(\mathrm{V})$ & 75 & 85 \\
UBM coils current $(\mathrm{A})$ & 3 & 4 \\
Coating thickness $(\mu \mathrm{m})$ & 2 & 1.5 \\
\hline
\end{tabular}

Observations of individual sprayed splats, metallographic cross-sections of the full coatings and fracture surfaces of the tested samples were performed in an EVO MA15 scanning electron microscope 
(Carl Zeiss, Oberkochen, Germany) in backscattered and/or secondary electron modes. Elemental analysis was performed by energy-dispersive spectroscopy (EDS) in the SEM, using an XFlash 5010 detector (Bruker, Berlin, Germany). Post-mortem analysis of the shear test samples was focused on the fracture location-either through the coating (coating cohesive failure), along the interface of coating-interlayer (coating adhesive failure) or along the interface of interlayer-substrate (interlayer adhesive failure). Detailed fractographic analysis of the fracture surfaces was also performed.

\section{Results and Discussion}

\subsection{Observations of Single Splats}

Since the first splats deposited on the substrate form the coating-substrate interface, attention was paid to their morphology and the conditions of their formation. An overview of the isolated splat deposited on four different substrates - polished steel, grit-blasted steel, polished steel with Ti and W interlayers - is shown in Figure 1. While in the first three cases, a multitude of tungsten splats is seen, on the $\mathrm{W}$-coated polished steel, most of the features are empty impact marks, indicating particle rebound. The marks were made visible by condensates of tungsten oxide vapor surrounding the impacting particles (see below for compositional analysis). Such impact marks were also observed on the polished steel substrate, at the periphery of the deposition trace, where the impinging particles are generally colder and slower.

Figure 1. Overview of isolated splats deposited on (a) grit-blasted steel, (b) polished steel, (c) Ti-coated polished steel and (d) W-coated polished steel substrates. Backscattered electron images.

(a)

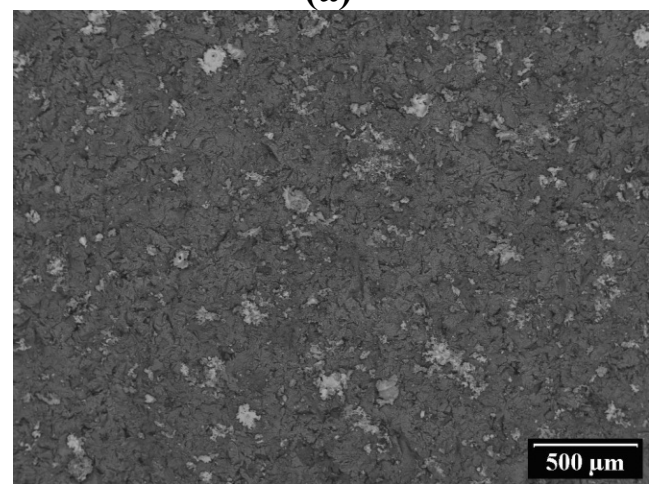

(c)

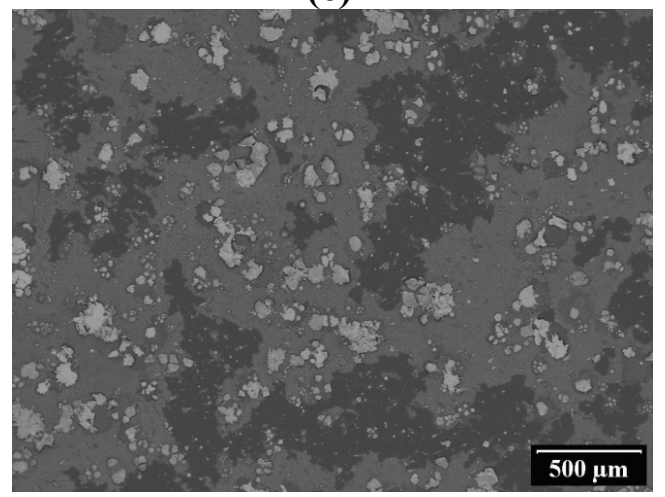

(b)

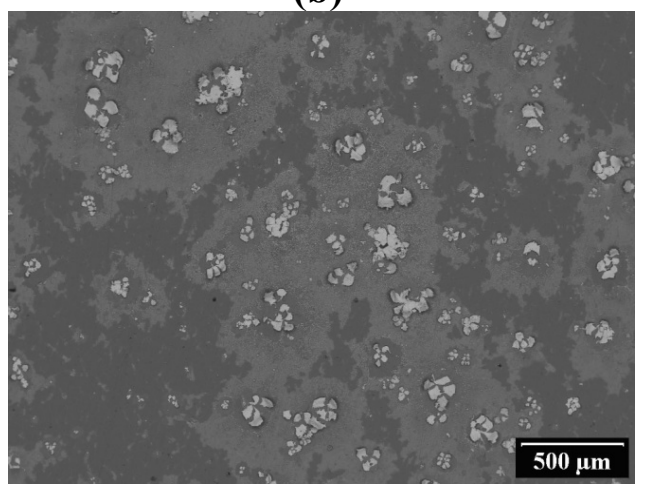

(d)

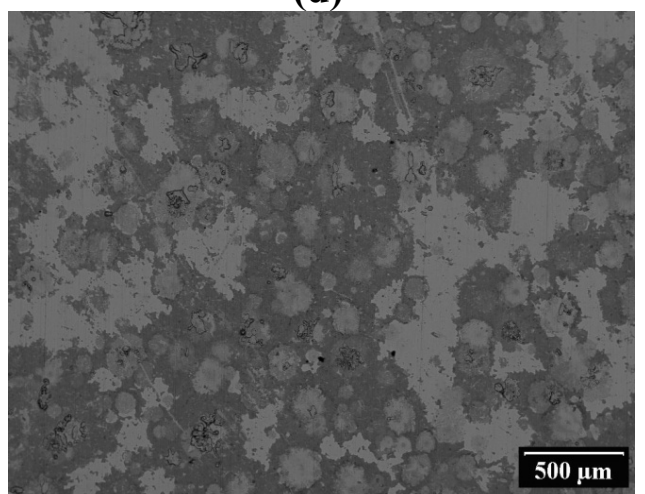


Details of representative splats on these four substrates are shown in Figure 2. A common feature of the splats on all four substrates is their somewhat irregular shape, but without extensive splashing projections ("fingers"). Moreover, the volume of the splats (estimated from their diameter and the thickness determined on the coating cross-section) appears significantly smaller than that of the feedstock. The material loss could have occurred by evaporation during flight and/or by splashing upon impact, if the splashed droplets did not adhere. Droplet fragmentation in-flight is unlikely under these conditions, as shown in [35]. Occasionally, bubbles were observed near the center of some splats, indicating that adsorbates were not completely removed by the preheat run. As can be seen from Figure 2, the morphology and composition of the substrate surface has a significant effect on the splat morphology. The splats formed on grit-blasted steel had the most irregular shape, with a jagged perimeter and often a jagged surface as well. The splats on all the other substrates had a smoother surface. On bare polished steel, fragmentation of the splats was frequently observed. This is probably a consequence of local substrate melting under the splat, while the tungsten fragments (likely in a semi-solid state, with a solid bottom and still liquid top) were gliding on the thin layer of liquid steel outwards from the center. This was also observed in [36]. Still, contiguous splats were frequently seen on this substrate.

Figure 2. Detailed view of representative splats deposited on (a) grit-blasted steel, (b) polished steel, (c) Ti-coated polished steel and (d) W-coated polished steel substrates. Backscattered electron (a-c) and secondary electron (d) images.

(a)

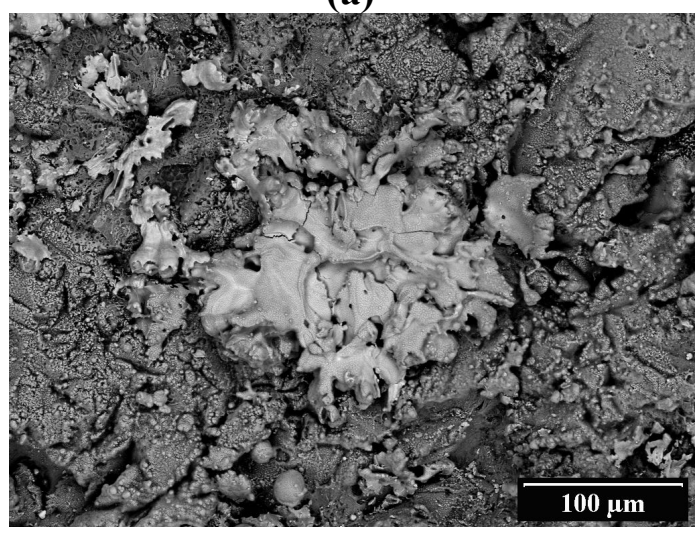

(c)

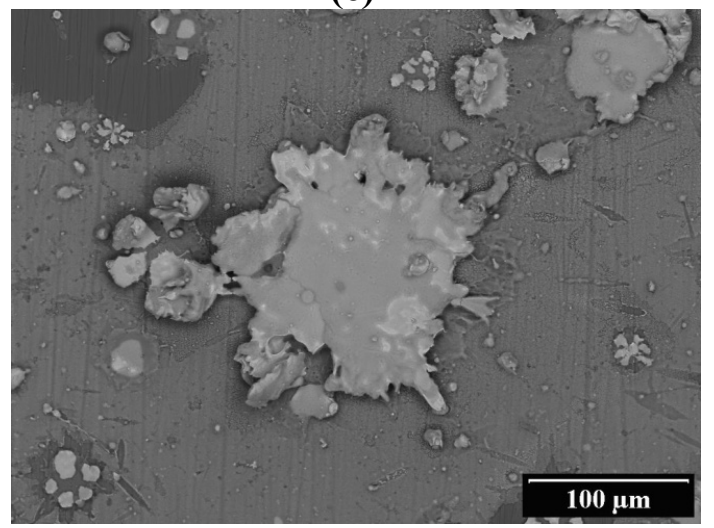

(b)

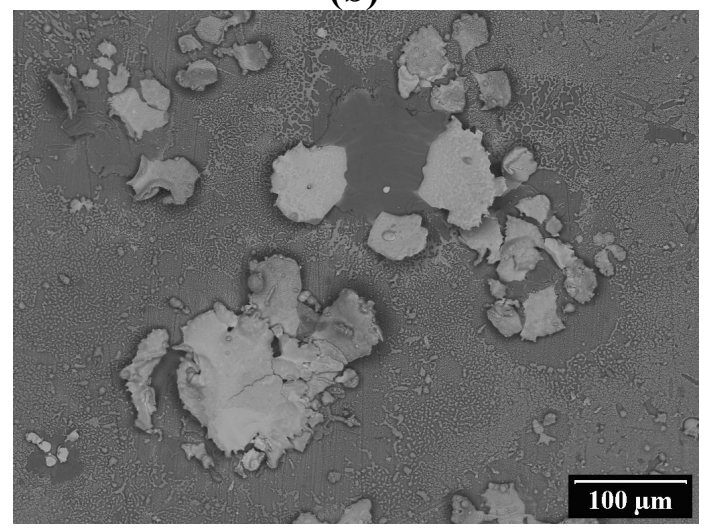

(d)

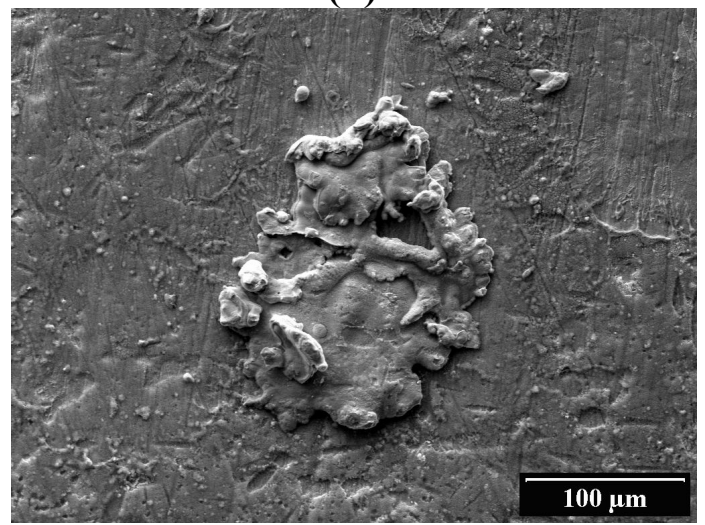


Figure 3. Detailed view of splats with interesting features; (a) smooth and contiguous splat deposited on top of a fragmented splat (polished steel), (b) detail of tungsten oxide condensates around a splat (polished steel), (c) larger contiguous splat (surrounded by fragmented smaller splats), with a distinct area of maximum spread and recoil, and region of molten steel substrate (Ti-coated polished steel), (d) detailed morphology of tungsten oxide on top of tungsten splat (W-coated polished steel), (e) irregular, recoiled splat with bubbles in the center (W-coated polished steel), (f) nearly disk-shaped, but slightly splashed splat, with a distinct area of maximum spread and recoil (W-coated polished steel). The numbers in $\mathrm{b}$, c, e correspond to locations of elemental analysis presented in Table 3. Backscattered electron $(\mathrm{a}-\mathrm{c}, \mathrm{e}, \mathrm{f})$ and secondary electron $(\mathrm{d})$ images.

(a)

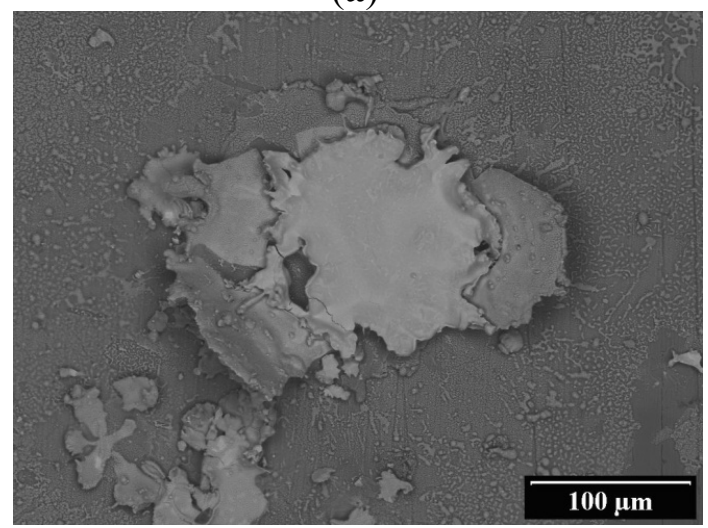

(c)

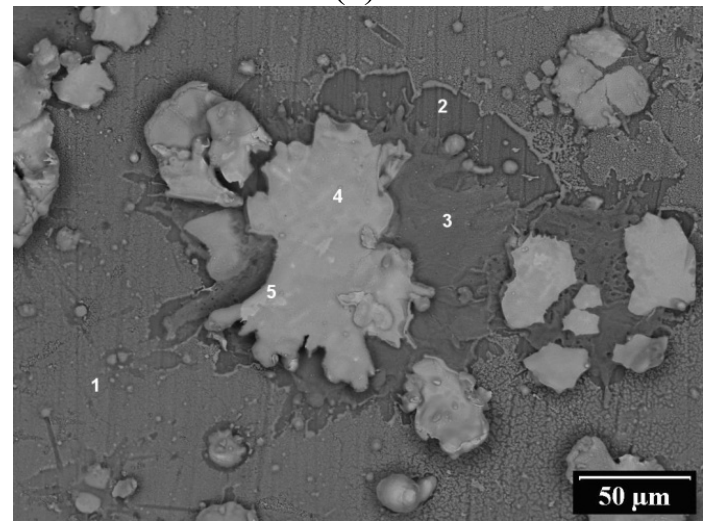

(e)

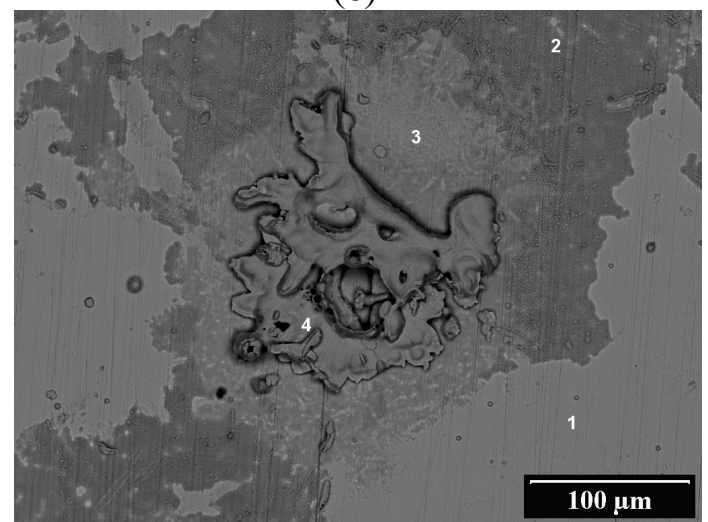

(b)

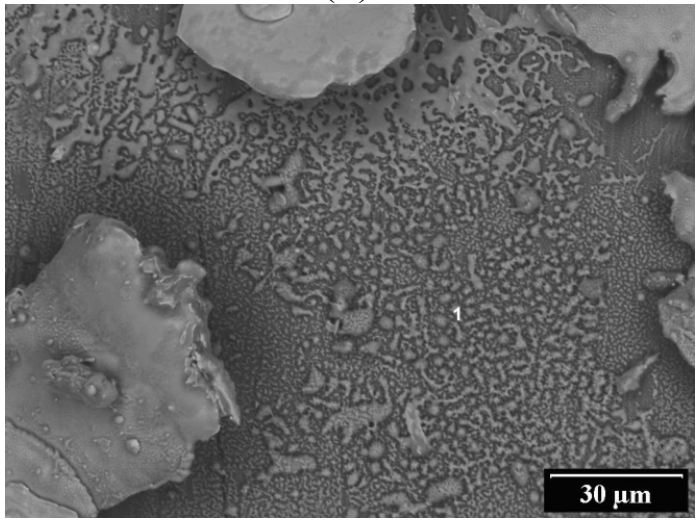

(d)

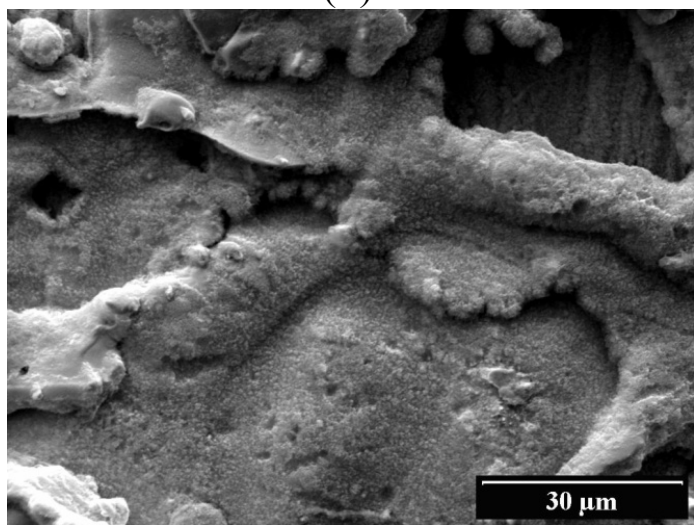

(f)

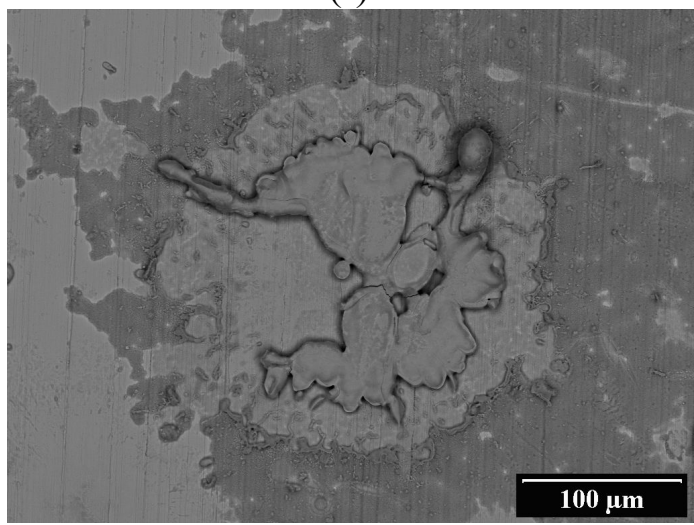


On Ti-coated polished substrate, splat fragmentation was also observed, but less frequently, while the majority of the splats were contiguous. The tungsten particles were able to melt through the thin Ti layer and cause local melting and jetting of the steel substrate under/around the impact point, as shown by the microanalysis (see below). The splats deposited on $\mathrm{W}$-coated polished substrate had a much less regular surface than in the cases above, but no fragmentation was observed. Also, no signs of substrate melting were found. On both Ti-coated and W-coated polished steel, splat recoil was sometimes observed. The diameter of the splat at the largest spread is indicated by the boundary between unaffected (outside of the splat) and affected (under the splat before the recoil) tungsten oxide deposit (Figure 3c,e,f).

Table 3. Summary of local elemental analysis (in wt $\%$ ) on the samples with isolated splats. In most cases, analyses were done on the same type of feature in several different locations, and the numbers represent average values. Representative locations are indicated by reference to numbered points in Figure 3. The values presented in this table should be taken as qualitative only, as the elements were heterogeneously distributed in the gauge volume (e.g., oxide of unknown thickness on the surface).

\begin{tabular}{|l|l|c|c|c|c|}
\hline Location & Feature & O & Ti & Fe & W \\
\hline Ti-coated polished steel & 24.9 & 43.8 & 2.2 & 29.1 \\
\hline Figure 3c-1 & substrate with $\mathrm{WO}_{3}$ deposit near splat & 20.5 & 67.4 & 2.0 & 10.1 \\
\hline Figure 3c-2 & substrate near recoiled splat & 8.4 & 5.0 & 75.1 & 11.5 \\
\hline Figure 3c-3 & jetted substrate near splat & 15.3 & 2.4 & 0.5 & 81.9 \\
\hline Figure 3c-4 & splat top & 9.7 & 1.4 & 0.4 & 88.6 \\
\hline Figure 3c-5 & splat top (brighter spot) & 2.1 & 95.5 & 1.7 & 0.7 \\
\hline & substrate away from splat & 2.0 & & 1.3 & 96.6 \\
\hline W-coated polished steel & 14.9 & & 1.2 & 83.9 \\
\hline Figure 3e-1 & substrate away from splat & 9.1 & & 0.9 & 90.0 \\
\hline Figure 3e-2 & substrate with $\mathrm{WO}_{3}$ deposit near splat & 5.8 & & 0.1 & 94.2 \\
\hline Figure 3e-3 & substrate near recoiled splat & & & \\
\hline Figure 3e-4 & splat top & 9.0 & & 90.6 & 0.4 \\
\hline Bare polished steel & substrate away from splat & 18.2 & & 49.5 & 32.3 \\
\hline & W impact mark & 12.5 & & 52.0 & 35.5 \\
\hline & 11.1 & & 1.9 & 87.0 \\
\hline Figure 3b-1 & substrate with $\mathrm{WO}_{3}$ deposit near splat & 15.6 & & 4.2 & 80.2 \\
\hline & splat top (brighter spot) & 7.2 & & 80.2 & 12.6 \\
\hline & splat top & & & \\
\hline & jetted substrate near splat & & & \\
\hline
\end{tabular}

Results of local elemental analysis are presented in Table 3. Significant presence of oxygen was found on both the substrates and the deposited splats. Signs of oxidation can be seen on the micromorphology of the splats and substrates as well, as a consequence of high temperature excursion during deposition. Although the deposition temperature was kept below $250{ }^{\circ} \mathrm{C}$ between torch passes, the surface temperature increased locally to much higher values just under the plasma jet. The areas with the highest oxygen content corresponded to $\mathrm{WO}_{3}$ vapor deposits surrounding the splat. In some areas, these condensed into $\mu \mathrm{m}$-sized droplets on the surface (Figure $3 \mathrm{~b}$ ). The oxygen content was somewhat 
reduced under fully spread and then recoiled splat (Figure 3c, point 2 and 3e, point 3). Intermediate oxygen content was observed on the splat surfaces, with heterogeneous distribution (the brighter areas in Figs. $2 \mathrm{c}$ and $3 \mathrm{c}$ had generally lower oxygen content). The lowest oxygen content was found on the substrates farther away from the splats. Dominant content of iron in the jetting metal under the splats (e.g., point 3 in Figure 3c, Ti-coated steel) confirms that these features consist of molten steel and not the Ti interlayer. On the surface of the W splats, a non-negligible amount of Ti and Fe was detected (of the order of percents), indicating that some material transfer from the respective substrate surfaces occurred. Possible mechanisms could be the splat recoil or diffusion + convection in the liquid. Some evaporation of the substrate material cannot be completely ruled out, as the boiling points of $\mathrm{Ti}$ and $\mathrm{Fe}$ are below the melting temperature of $\mathrm{W}\left(3287^{\circ} \mathrm{C}, 2861^{\circ} \mathrm{C}\right.$ and $3422^{\circ} \mathrm{C}$, respectively) [37].

\subsection{Observations of Coating and Interface Cross-Sections}

Figure 4a shows a typical microstructure of the PS tungsten coatings. The coating has a characteristic lamellar microstructure created by solidified splats, voids (crack-like intersplat and intrasplat pores and irregular pores within the splat boundaries) and oxides (often present at the intersplat boundaries). Despite the differences in shapes of the first layer of splats, the lamellar structure throughout the coatings was very similar for all the substrates. Figure $4 \mathrm{~b}$ shows interface detail of a sample with roughened substrate surface without a PVD interlayer; dark areas at the interface are residual alumina grits embedded in the substrate after grit blasting. It can be noticed that the splats were able to fill well even shielded surface irregularities, thus creating an efficient "dovetail" interlocking. Figure 4c shows the interface of a roughened substrate surface with a titanium PVD layer. The layer copied the surface irregularities precisely. Different grey levels within the interface layer suggest that diffusion took place between the substrate/layer/coating materials. Unfortunately, the resolution of the EDS analysis was not sufficient to properly examine this area; however, phase diagrams and literature suggest a possible presence of $\mathrm{FeTi}$ or $\mathrm{Fe}_{2} \mathrm{Ti}$ at the substrate/layer interface $[31,38]$ and solid solution of $\mathrm{W}$ and $\mathrm{Ti}$ at the layer/coating interface [39]. Depending on the local surface conditions and the state of impacting particle, interfaces of different qualities were developed. Figures $5 \mathrm{a}, \mathrm{b}$ shows the interface regions with a different extent of $\mathrm{Fe} / \mathrm{Ti}$ interdiffusion and the corresponding EDS line scans. While Figure 5a documents the interface where the original material (Ti) is still largely preserved, Figure $5 \mathrm{~b}$ shows the interface where diffusion took place in the whole thickness of the layer. Figure $4 \mathrm{~d}$ shows the substrate interface with a tungsten PVD layer. Also the tungsten layer had no substantial influence on the surface roughness. The tungsten layer fills well irregularities of the substrate; however, it seems its adherence to the substrate was lower-places of local debonding were observed, probably due to alumina grit residues (marked by red arrow). Regarding the layer/coating interface, direct contact of the coating with the PVD layer was hindered by an oxide scale (marked by white arrows). Figure 6b shows a map of oxygen over the interface area (in Figure 6a); the region of the oxidized tungsten is apparent at the interface (circled in Figure 6b), while the other regions mark the locations of residual grits. 
Figure 4. Representative microstructure and interfaces of Water Stabilized Plasma (WSP) sprayed tungsten. (a) WSP sprayed tungsten, (b) interface of a grit blasted substrate (R2), (c) interface with Ti layer, (d) interface with W layer.

(a)

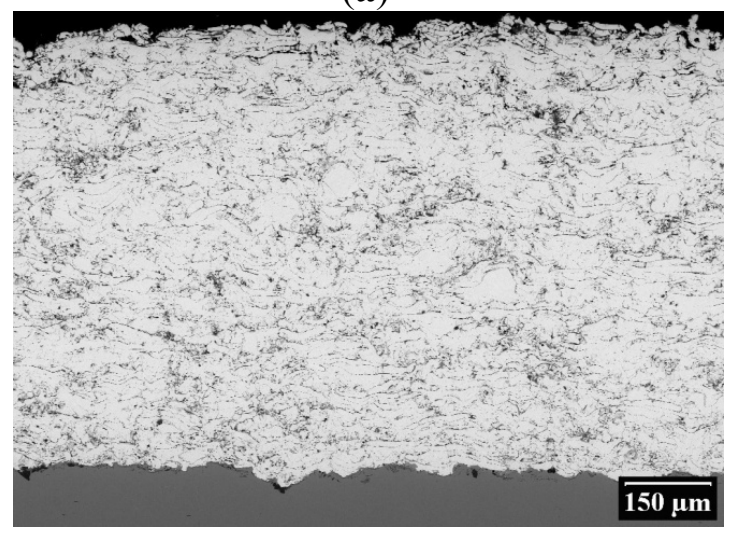

(c)

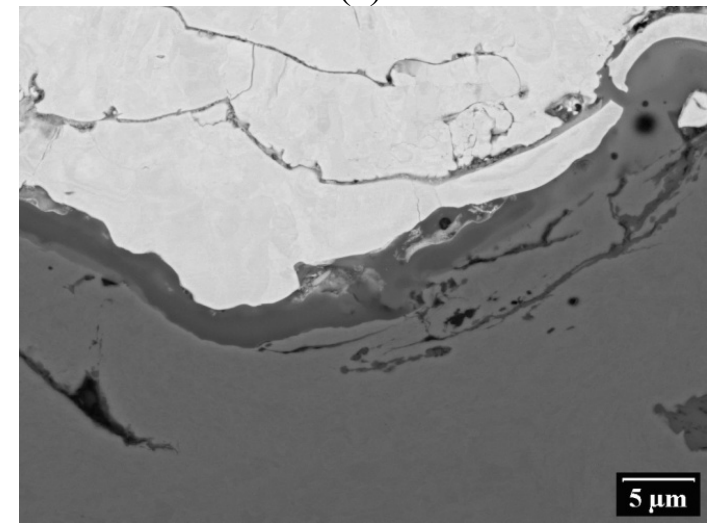

(b)

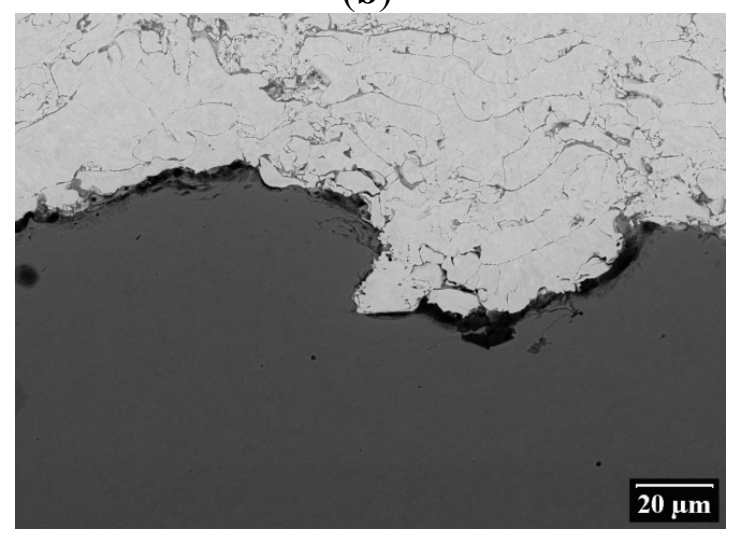

(d)

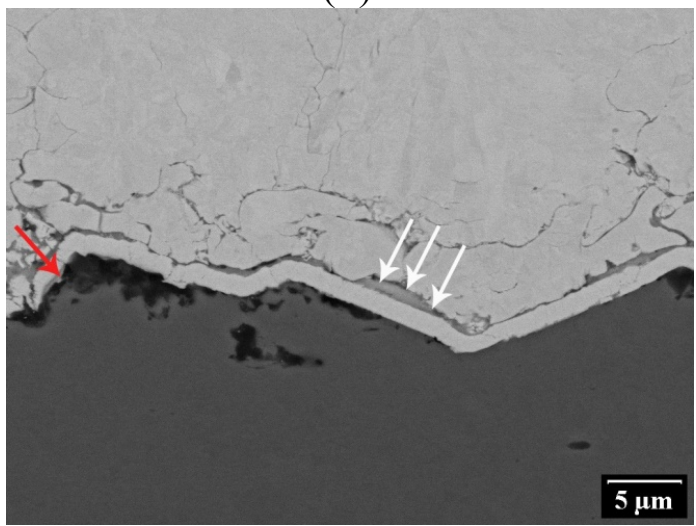

\subsection{Shear Adhesion Testing}

The results of shear adhesion testing are summarized in Figure 7, without W1 samples which debonded during the cooling process after the coating deposition. Differences due to the substrate roughness level, as well as presence/absence of the interlayer can be seen. Generally, the failure was cohesive for all tested samples. The only exceptions are T1 samples where the Ti layer was partially revealed (adhesive failure); however, the fraction of the adhesive failure was very minor. Neither was a debonding of the PVD layer observed. Therefore, it can be stated that for all the tested samples, coating adhesion was higher than its cohesion. The EN 15340 standard recognizes several modes of cohesion failure. Some tested sets of samples failed according to mode 2 (coating broke off the sample in one piece) and some according to mode 3 a (coating disintegrated into small pieces), Figure 7.

Considering the two different modes of failure and different values of cohesion within mode 2, it seems that the coatings, although having been sprayed in one run under identical spraying parameters, were somehow influenced by the surface treatment. To confirm this suspicion, the coatings were subjected to indentation loading using Vickers indenter and a weight of $1 \mathrm{~kg}$. The results in Figure 8 show a distinct response of the coatings to the applied loading, i.e., crack propagation and opening preferentially along the splat interfaces (red arrows) in the bare steel sample, crushing of splats (blue arrows) in the sample with $\mathrm{W}$ interlayer and combination of crushing and splat debonding in the sample with Ti interlayer. 
Thus, the coatings did not behave identically, despite having similar microstructures. This could be a result of different heat transfer from the coating to the substrate, caused by distinct properties of the PVD layers, different bonding quality between the PVD layers and the PS coating and by the presence of an oxide scale in the case of the tungsten layer.

Figure 5. Line scan over the interface with the Ti layer. (a) Limited diffusion, (b) significant diffusion.

(a)
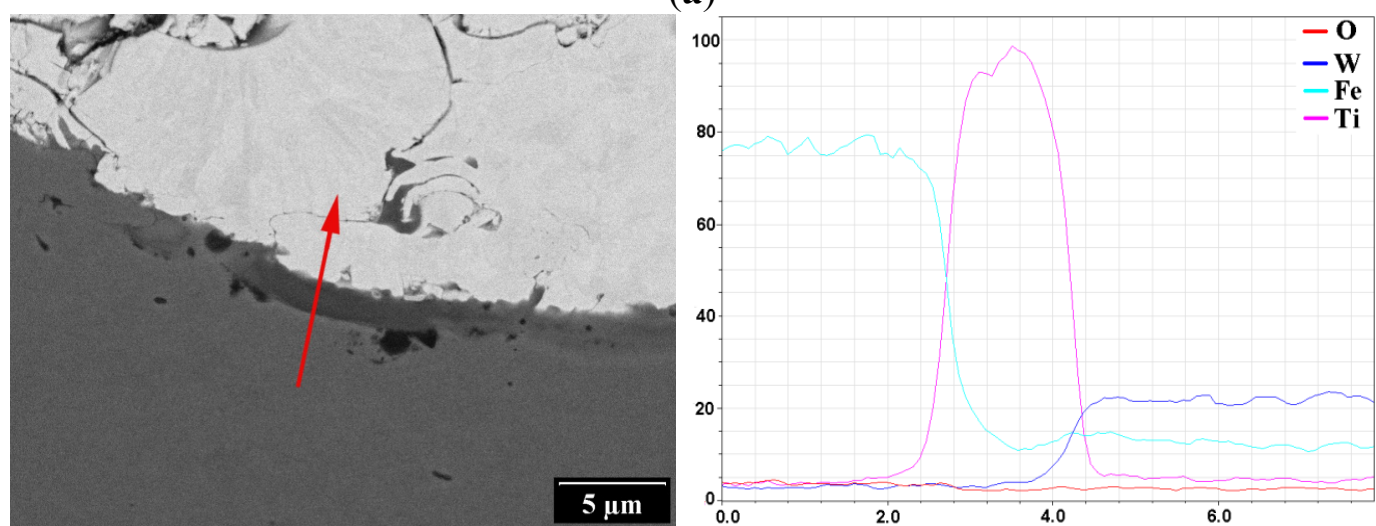

(b)
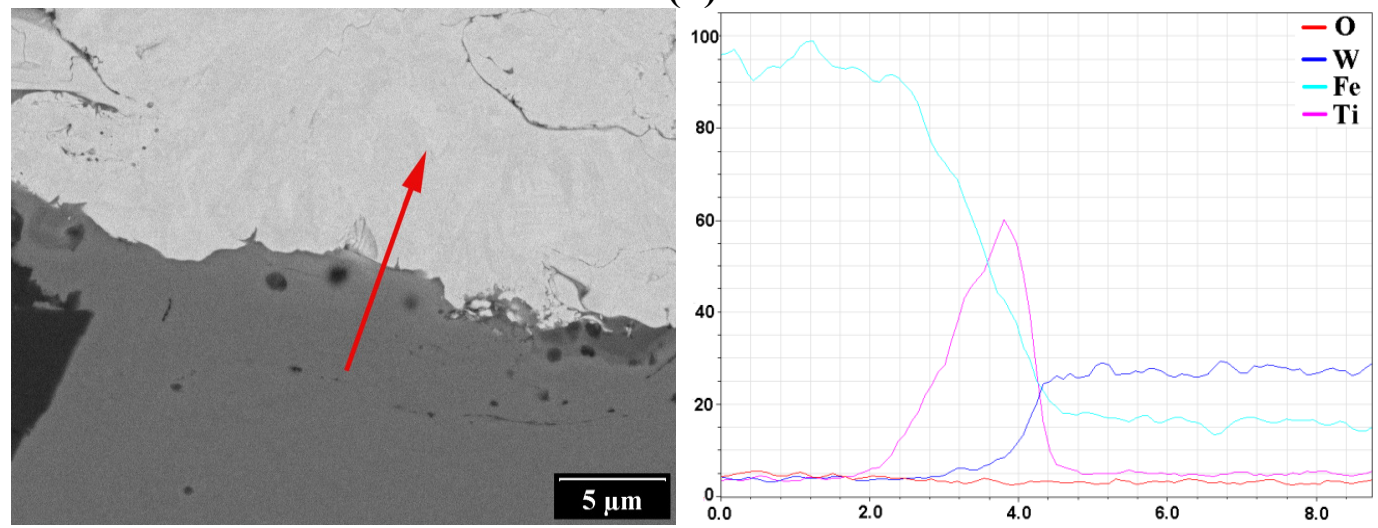

Figure 6. Energy-dispersive spectroscopy (EDS) oxygen mapping at the interface of the tungsten coating with tungsten physical vapor deposition (PVD) layer. (a) Backscattered electron image of the interface oxide, (b) oxygen map over the area in (a).

(a)

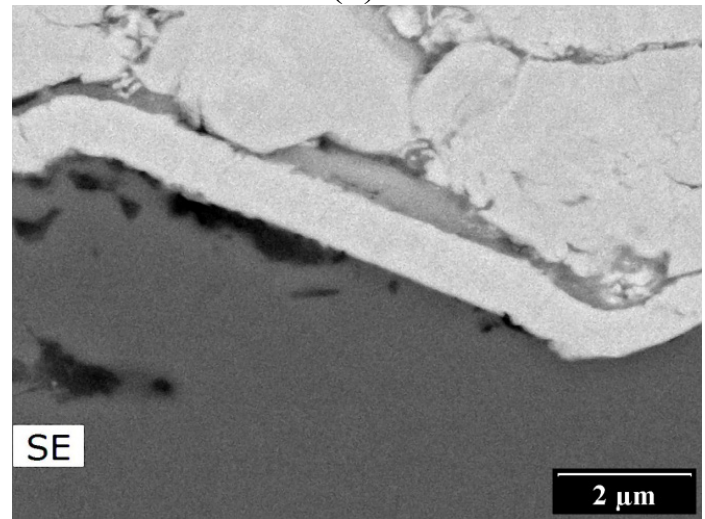

(b)

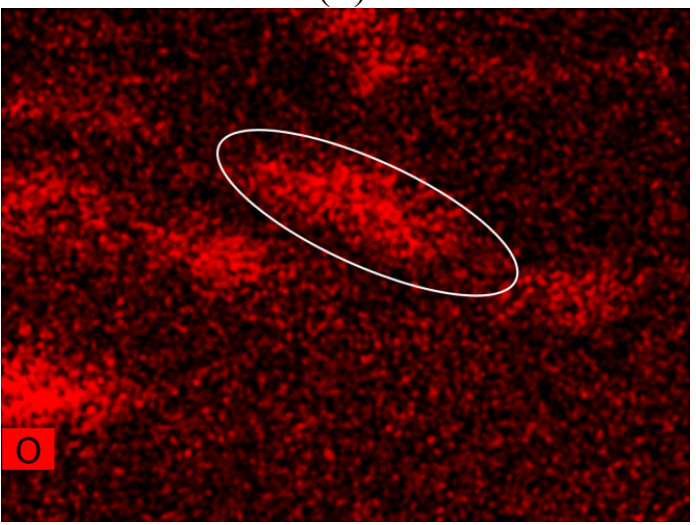


Figure 7. Shear strength of the tested coatings with the corresponding failure mode defined by EN 15340 .

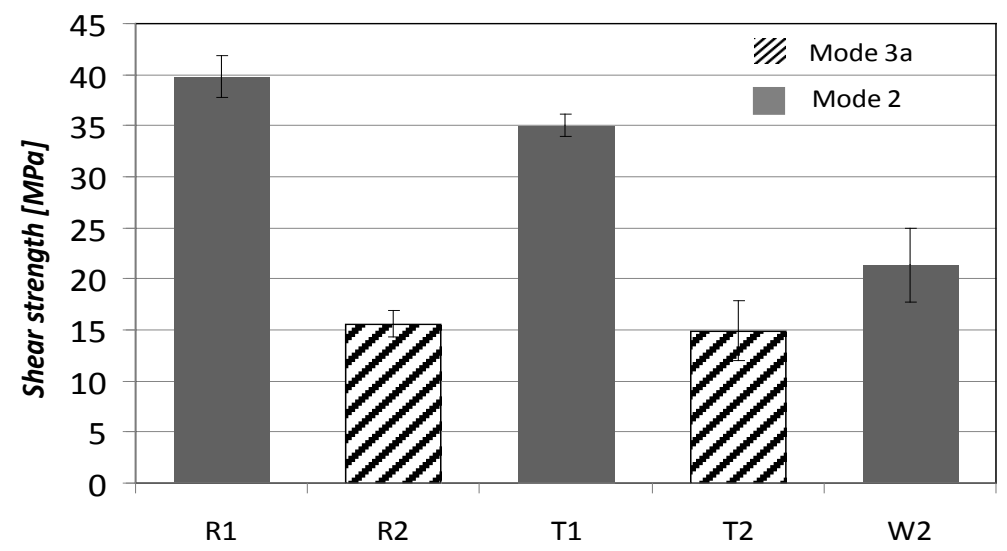

Figure 8. Indentation damage of coatings on grit blasted substrates.

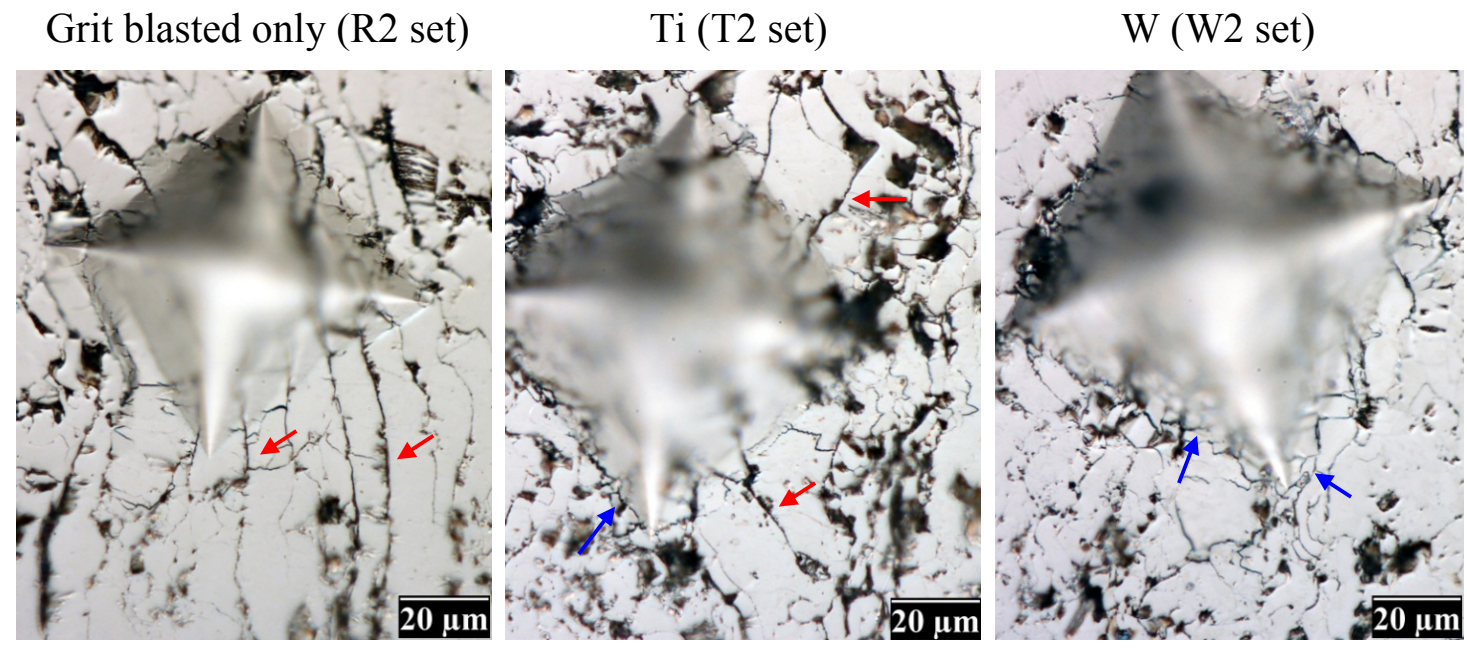

\subsection{Observations of Fracture Surfaces and Interfaces}

Figure 9 shows the fracture surface of a "T1 set" sample failed during the shear test. The micromorphological features are documented with the help of coupled micrographs showing corresponding areas on the substrate side (left column-SS) and coating side of the fracture surface (right column-CS). The failure of all tested coating sets was generally cohesive; only in the T1 set of samples, a minor part of the failure was also adhesive. Figure 9a offers a general view of the fracture surface with area of adhesive fracture (within the dashed line) and area of cohesive fracture (outside the dashed line) with corresponding fracture surface on the coating side (Figure 9a, CS). It can be noticed that the relief on the coating side of the fracture is more irregular than could be expected from the surface morphology on the substrate side. This might be due to the splash droplets resulting from the impacting tungsten particles [40]. Figure $9 \mathrm{~b}$ shows a detail of the adhesive fracture area (A in SS) and the coating detached from this area (A in CS). The area A reveals the presence of larger pores on both CS and SS sides, which could be a result of local overheating and escape of the surface adsorbates [41]. EDS analysis proved that the adhesive fracture occurred at the interface of the Ti interlayer and tungsten coating (Figure 10a, SS). 
Nevertheless, exposure of the Ti layer was rather rare; thus, also in the case of the T1 set, the coating adhesion strength was higher than the cohesion strength. Two areas on the coating detached from the Ti layer can be recognized from Figure 10-CS: EDS analysis of the first area (Figure 10a, CS, blue regions) revealed increased content of titanium which indicates titanium transfer to the coating material; the second area (Figure 10b, CS, green regions) shows large amount of oxides as well as titanium (Figure 10a, CS), which suggests that during adhesion failure, the oxide grown on the Ti layer (Figure 10b, SS) became debonded. Figure 9c documents typical signs of the cohesive fracture area which resulted mainly from a combination of splats decohesion (D) and splats breaking (B). Splat cohesion was often decreased by the presence of oxides at the intersplat boundaries due to their brittle nature and by the presence of voids (V).

Figure 9. SE images of fracture surface of a sample from $\mathrm{T} 1$ set; analysis using method of matching surfaces: left column-substrate side of the fracture, right column-coating side of the fracture.

\section{SUBSTRATE SIDE (SS)}

\section{COATING SIDE (CS)}

(a) General view of the fracture surface
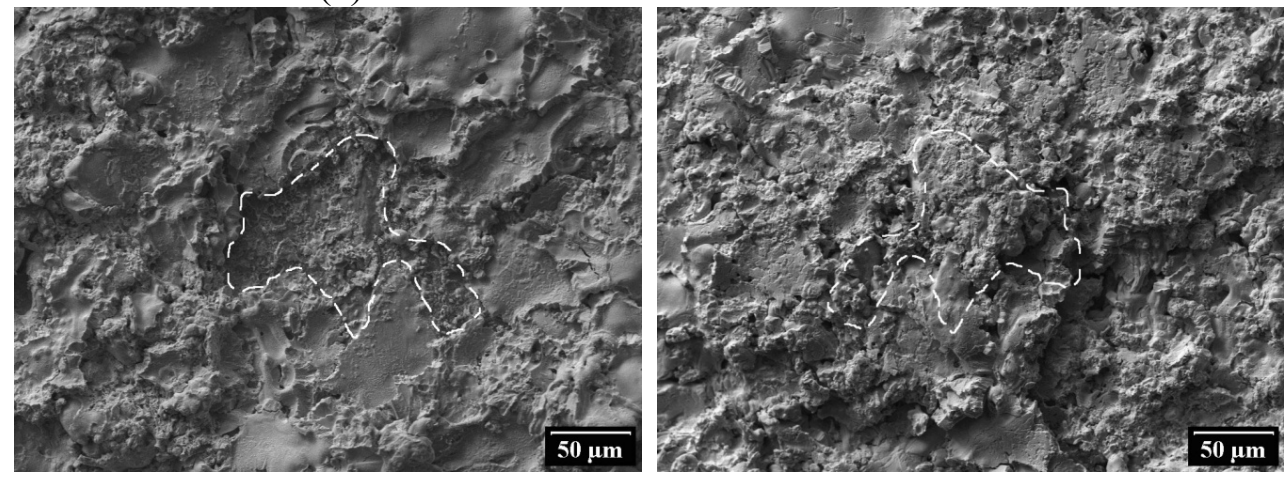

(b) Area of adhesion failure (Partially revealed substrate)
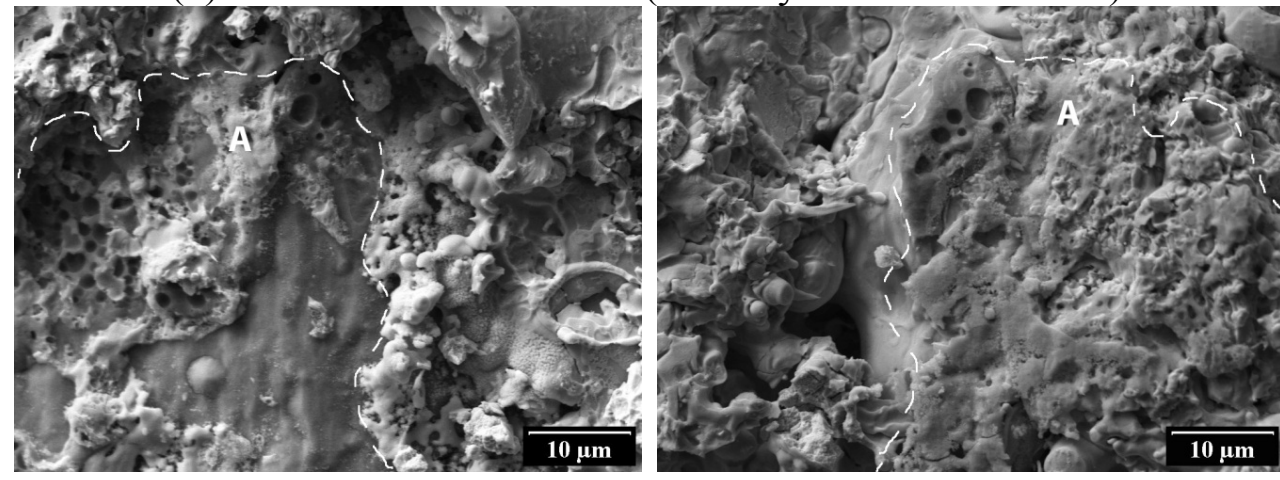

(c) Area of cohesion failure
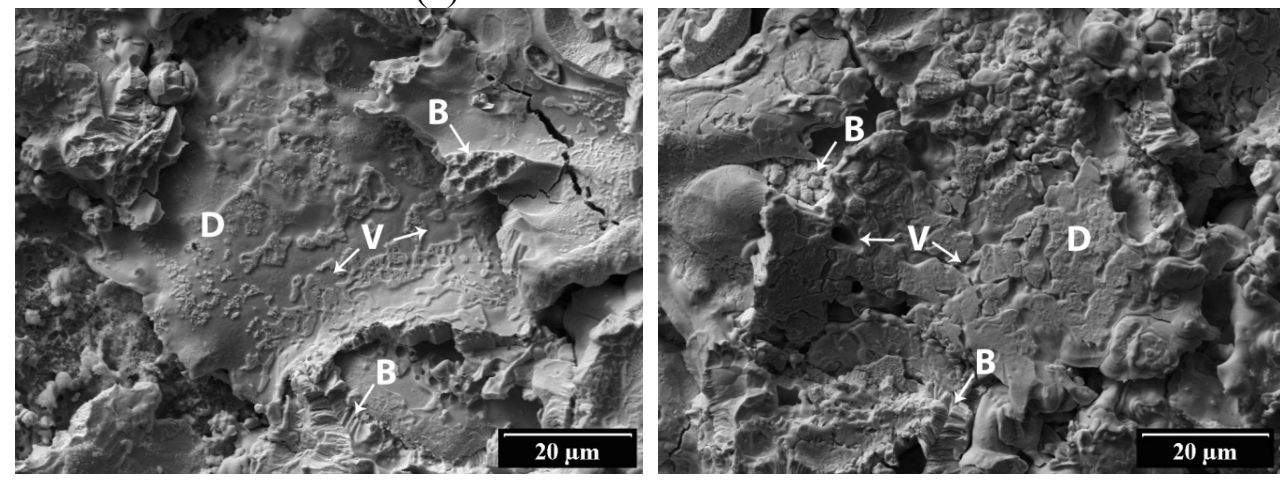
Figure 10. Elements distribution over fracture surface of a sample from T1 set.

SUBSTRATE SIDE (SS)

(a) $\mathrm{W}$ and Ti distribution
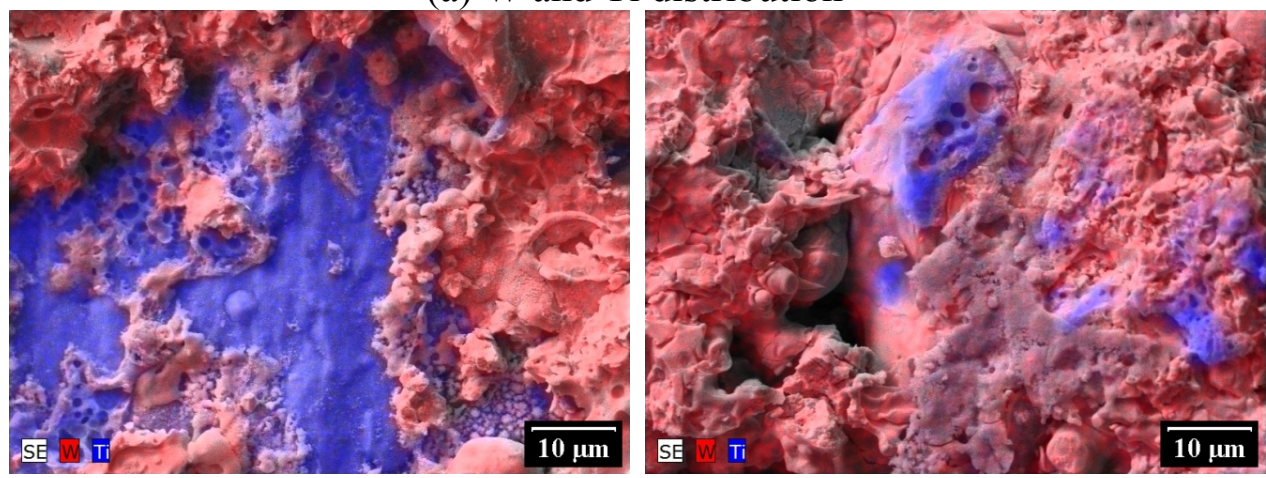

(b) O distribution
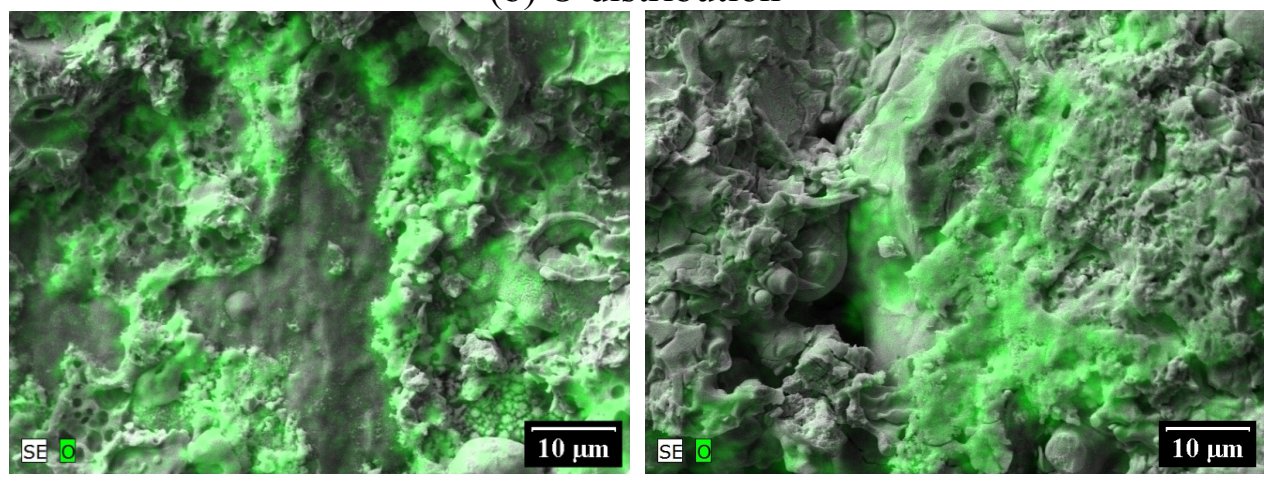

As all tested samples failed cohesively, it is not possible to directly compare their adhesion strength. Nevertheless, it is well known that the "diffusion bond" is one of the strongest possible bonding interactions [9]. It seems that the Ti-interlayer and tungsten coating can form such a bond and thus improve the coating-substrate adhesion. No diffusion bond was observed at the interface of samples with the tungsten interlayer, as the bond was probably hindered by a relatively thick oxide scale $\left(\mathrm{WO}_{3}\right)$ grown on the PVD layer. Moreover, detailed observations showed that the interface oxides were porous and brittle. Thus, it can be expected and was confirmed by the W1 set of samples that the tungsten layer did not have a positive effect on coating adhesion.

\section{Conclusions}

In this work, the effect of Ti and W interlayers deposited by a PVD technique on steel substrates with two different roughness levels was studied. The shear test of adhesion showed that for all samples, their cohesion strength was lower than the adhesion strength. Thus, it was not possible to quantify the combined effect of surface roughness and PVD layer on the adhesion of the plasma sprayed coatings. Nevertheless, the detailed characterization has shed some light on the phenomena taking place at the interface and allowed us to discuss the effect of interlayers. It is commonly accepted that mechanical interlocking is the main adhesion mechanism of thermal spray deposits $[9,14]$. However, the interlocking sites, as produced by the grit blasting process, might not offer sufficient adhesion, especially when coupling materials with significantly different properties. With its thermal expansion lying between steel and tungsten, titanium seems to be a promising candidate for improving the adhesion 
of tungsten coatings. Based on the observations in this study, it can be concluded that a PVD titanium layer has a positive effect on the adhesion of a plasma sprayed tungsten coating due to the formation of a strong diffusion bond and the suppressed effect of titanium oxidation. The titanium layer itself exhibits features conducive to good adhesion to the substrate material: diffusion between the steel substrate and titanium, no significant oxide layer between substrate and titanium as well as no gaps/voids were present at the interface. It was also observed that the PVD layer did not significantly change the roughness of the underlying substrate. Therefore, the positive effect of the substrate roughness can be preserved [11].

The PVD tungsten layer did not adhere properly to the substrate; moreover, a relatively thick scale of brittle and porous oxide covered its surface during the plasma spraying process. Considering the early failure of W1 samples and the properties of tungsten oxide, a positive effect on coating adhesion cannot be expected. In the case of W2 samples with a higher initial substrate roughness, increased adherence of the coating can be attributed to a more effective interlocking mechanism on the surface asperities.

In summary, the positive effect of substrate roughness and of the Ti interlayer was demonstrated in this work. Further improvement of the coating adhesive/cohesive strength may be achieved by a combination of a $\mathrm{Ti}$ interlayer with increased substrate roughness, and suppression of oxidation during spraying.

\section{Acknowledgments}

This work was partially supported by the following grants: P108/12/1872 (Czech Science Foundation), WP12-MAT-01-HHFM (EU through European Fusion Development Agreement) and FR-TI2/702 (Czech Ministry of Industry and Trade). The views and opinions expressed herein do not necessarily reflect those of the European Commission.

\section{References}

1. Romanelli, F.; Barabaschi, P.; Borba, D.; Federici, G.; Horton, L.; Neu, R.; Stork, D.; Zohm, H. Fusion Electricity-A Roadmap to the Realisation of Fusion Energy; European Fusion Development Agreement: Garching, Germany, 2012.

2. Bolt, H.; Barabash, V.; Krauss, W.; Linke, J.; Neu, R.; Suzuki, S.; Yoshida, N. Materials for the Plasma-Facing Components of Fusion Reactors. J. Nucl. Mater. 2004, 329, 66-73.

3. Davis, J.W.; Barabash, V.R.; Makhankov, A.; Plochl, L.; Slattery, K.T. Assessment of Tungsten for Use in the ITER Plasma Facing Components. J. Nucl. Mater. 1998, 263, 308-312.

4. Smid, I.; Akiba, M.; Vieider, G.; Plöchl, L. Development of Tungsten Armor and Bonding to Copper for Plasma- Interactive Components. J. Nucl. Mater. 1998, 263, 160-172.

5. Pintsuk, G. Tungsten as a Plasma-Facing Material. In Comprehensive Nuclear Materials; Konings, R.J.M., Ed.; Elsevier: Amsterdam, The Netherland, 2012; pp. 551-581.

6. Maier, H.; Neu, R.; Greuner, H.; Böswirth, B.; Balden, M.; Lindig, S.; Matthews, G.F.; Rasinski, M.; Wienhold, P.; Wiltner, A. Qualification of Tungsten Coatings on Plasma-Facing Components for JET. Phys. Scr. 2009, T138, paper no. 014031.

7. Matějíček, J.; Chráska, P.; Linke, J. Thermal Spray Coatings for Fusion Applications-Review. J. Thermal Spray Technol. 2007, 16, 64-83. 
8. Matějíček, J.; Koza, Y.; Weinzettl, V. Plasma Sprayed Tungsten-based Coatings and their Performance under Fusion Relevant Conditions. Fusion Eng. Des. 2005, 75-79, 395-399.

9. Weiss, H. Adhesion of Advanced Overlay Coatings-Mechanisms and Quantitative Assessment. Surf. Coat. Technol. 1995, 71, 201-207.

10. Sobolev, V.V.; Guilemany, J.M.; Nutting, J.; Miquel, J.R. Development of Substrate-Coating Adhesion in Thermal Spraying. Int. Mater. Rev. 1997, 42, 117-136.

11. Mellali, M.; Fauchais, P.; Grimaud, A. Influence of Substrate Roughness and Temperature on the Adhesion/Cohesion of Alumina Coatings. Surf. Coat. Technol. 1996, 81, 275-286.

12. Staia, M.H.; Ramos, E.; Carrasquero, A.; Roman, A.; Lesage, J.; Chicot, D.; Mesmacque, G. Effect of Substrate Roughness Induced by Grit Blasting Upon Adhesion of WC-17\% Co Thermal Sprayed Coatings. Thin Solid Films 2000, 377, 657-664.

13. Vilémová, M.; Siegl, J.; Matějíček, J.; Mušálek, R. Effect of the Grit Blasting Exposure Time on the Adhesion of $\mathrm{Al}_{2} \mathrm{O}_{3}$ and 316L Coatings. In Thermal Spray 2011: Proceedings of the International Thermal Spray Conference (DVS-ASM), Hamburg, Germany, 2011; pp. 979-984.

14. Wang, Y.Y.; Li, C.J.; Ohmori, A. Influence of Substrate Roughness on the Bonding Mechanisms of High Velocity Oxy-Fuel Sprayed Coatings. Thin Solid Films 2005, 485, 141-147.

15. Paredes, R.S.C.; Amico, S.C.; d'Oliveira, A.S.C.M. The Effect of Roughness and Pre-Heating of the Substrate on the Morphology of Aluminium Coatings Deposited by Thermal Spraying. Surf. Coat. Technol. 2006, 200, 3049-3055.

16. Dallaire, S. Influence of Temperature on the Bonding Mechanism of Plasma-Sprayed Coatings. Thin Solid Films 1982, 95, 237-244.

17. Fukumoto, M.; Huang, Y. Flattening Mechanism in Thermal Sprayed Nickel Particle Impinging on Flat Substrate Surface. J. Thermal Spray Technol. 1999, 8, 427-432.

18. Jiang, X.Y.; Wan, Y.P.; Herman, H.; Sampath, S. Role of Condensates and Adsorbates on Substrate Surface on Fragmentation of Impinging Molten Droplets During Thermal Spray. Thin Solid Films 2001, 385, 132-141.

19. Qu, M.; Gouldstone, A. On the Role of Bubbles in Metallic Splat Nanopores and Adhesion. $J$. Thermal Spray Technol. 2008, 17, 486-494.

20. Tran, A.T.T.; Hyland, M.M.; Shinoda, K.; Sampath, S. Influence of Substrate Surface Conditions on the Deposition and Spreading of Molten Droplets. Thin Solid Films 2011, 519, 2445-2456.

21. McDonald, A.; Moreau, C.; Chandra, S. Thermal Contact Resistance between Plasma-Sprayed Particles and Flat Surfaces. Int. J. Heat Mass Transfer 2007, 50, 1737-1749.

22. Brossard, S.; Munroe, P.R.; Tran, A.T.T.; Hyland, M.M. Study of the Effects of Surface Chemistry on Splat Formation for Plasma Sprayed NiCr onto Stainless Steel Substrates. Surf. Coat. Technol. 2010, 204, 1599-1607.

23. Sabiruddin, K.; Bandyopadhyay, P.P.; Bolelli, G.; Lusvarghi, L. Variation of Splat Shape With Processing Conditions in Plasma Sprayed Alumina Coatings. J. Mater. Process. Technol. 2011, 211, 450-462.

24. Li, C.J.; Yang, G.J.; Li, C.X. Development of Particle Interface Bonding in Thermal Spray Coatings: A Review. J. Thermal Spray Technol. 2013, 22, 192-206.

25. Cho, G.S.; Choe, K.H. Characterization of Plasma-Sprayed Tungsten Coating on Graphite with Intermediate Layers. Surf. Coat. Technol. 2012, 209, 131-136. 
26. Chong, F.L. Optimization of Plasma-Sprayed Tungsten Coating on Copper with the Heterogeneous Compliant Layer for Fusion Application. J. Thermal Spray Technol. 2013, 22, 57-60.

27. Matějíček, J.; Mušálek, R. Processing and Properties of Plasma Sprayed $\mathrm{W}+\mathrm{Cu}$ Composites. In Thermal Spray 2008: Crossing Borders (DVS-ASM), Maastricht, The Netherland, 2008; pp. 1400-1405.

28. Matějíček, J.; Boldyryeva, H. Processing and Temperature-Dependent Properties of Plasma Sprayed Tungsten-Stainless Steel Composites. Phys. Scr. 2009, T138, paper no. 014041.

29. Niu, Y.R.; Hu, D.Y.; Ji, H.; Huang, L.P.; Zheng, X.B. Effect of Bond Coatings on Properties of Vacuum Plasma Sprayed Tungsten Coatings on Copper Alloy Substrate. Fusion Eng. Des. 2011, 86, 307-311.

30. Weber, T.; Stüber, M.; Ulrich, S.; Vassen, R.; Basuki, V.; Lohmiller, J.; Sittel, W.; Aktaa, J. Functionally Graded Vacuum Plasma Sprayed and Magnetron Sputtered Tungsten/EUROFER97 Interlayers for Joints in Helium-Cooled Divertor Components. J. Nucl. Mater. 2013, in press.

31. Jung, Y.-I.; Park, J.-Y.; Choi, B.-K.; Lee, D.-W.; Cho, S. Interfacial Microstructures of HIP Joined $\mathrm{W}$ and Ferritic-Martensitic Steel with Ti Interlayers. Fusion Eng. Des. 2013, in press.

32. Matějíček, J.; Neufuss, K.; Kolman, D.; Chumak, O.; Brožek, V. Development and Properties of Tungsten-Based Coatings Sprayed by WSP(R). In International Thermal Spray Conference, Basel, Switzerland, 2005; pp. 634-640

33. EN15340: Thermal spraying-Determination of Shear Load Resistance of Thermally Sprayed Coatings; European Committee for Standardization: Brussels, Belgium, 2007.

34. Mušálek, R.; Pejchal, V.; Vilémová, M.; Matějiček, J. Multiple-Approach Evaluation of WSP Coatings Adhesion/Cohesion Strength. J. Thermal Spray Technol. 2013, 22, 221-232

35. Matějíček, J.; Kavka, T.; Bertolissi, G.; Ctibor, P.; Vilémová, M.; Mušálek, R.; Nevrlá, B. The Role of Spraying Parameters and Inert Gas Shrouding in Hybrid Water-Argon Plasma Spraying of Tungsten and Copper for Nuclear Fusion Applications. J. Thermal Spray Technol. 2013, 22, 744-755.

36. Kavka, T.; Matějíček, J.; Ctibor, P.; Hrabovský, M. Spraying of Metallic Powders by Hybrid Gas/Water Torch and the Effects of Inert Gas Shrouding. J. Thermal Spray Technol. 2012, 21, 695-705.

37. Web Elements. Available online: http://www.webelements.com (accessed on 15 April 2013).

38. Zhou, G.J.; Zeng, D.C.; Liu, Z.W. Phase Equilibria in the Fe-Ti-Zr System at 1023 K. J. Alloys Compd. 2010, 490, 463-467.

39. Calculated Ti-W phase diagram. Available online: http://resource.npl.co.uk/mtdata/phdiagrams/ tiw.htm (accessed on 15 April 2013).

40. Niu, Y.R.; Zheng, X.B.; Ji, H.; Qi, L.J.; Ding, C.X.; Chen, J.L.; Luo, G.N. Microstructure and Thermal Property of Tungsten Coatings Prepared by Vacuum Plasma Spraying Technology. Fusion Eng. Des. 2010, 85, 1521-1526.

41. Tran, A.T.T.; Hyland, M.M. Bubble Formation in NiCr Splat on Aluminum Substrate during Plasma Spray: Surface Chemistry Effect. IOP Conf. Ser. Mater. Sci. Eng. 2009, paper no. 012007.

(C) 2013 by the authors; licensee MDPI, Basel, Switzerland. This article is an open access article distributed under the terms and conditions of the Creative Commons Attribution license (http://creativecommons.org/licenses/by/3.0/). 